\title{
Activity of ciprofloxacin against genital tract pathogens
}

\author{
C ANTHONY HART, SIMON J HOW, AND DEREK HOBSON \\ From the Department of Medical Microbiology, University of Liverpool, Liverpool
}

SUMMARY The in vitro activity of the quinolone carboxylic acid, ciprofloxacin, against a variety of genital tract pathogens was examined. Each of 35 isolates of Neisseria gonorrhoeae, including some $\beta$-lactamase producing strains and strains resistant to tetracycline, was inhibited at a concentration of $0.01 \mathrm{mg} / 1$. Most (13 of 20) strains of Gardnerella vaginalis were inhibited at $1 \mathrm{mg} / \mathrm{l}$ but three isolates had minimum inhibitory concentrations (MICs) of $8 \mathrm{mg} / 1$ or more. Each of seven strains of Chlamydia trachomatis was completely inhibited at a concentration of $2 \mathrm{mg} / \mathrm{l}$. Prolonged ( 72 hours) exposure of the chlamydiae to ciprofloxacin was required for inhibition at this concentration.

\section{Introduction}

The antimicrobial chemotherapy of sexually transmitted diseases (STDs) has become more complex with the emergence of $\beta$-lactamase producing Neisseria gonorrhoeae ${ }^{1}$ and the recognition of the importance of Chlamydia trachomatis ${ }^{2}$ and Gardnerella vaginalis ${ }^{3}$ as important pathogens in genital tract infections. As STDs caused by different pathogens are frequently concurrent, especially in women patients, treatment with a single antibiotic with a broad spectrum of activity against these agents would be of great clinical value. With this in mind we have examined the in vitro activity of ciprofloxacin, a quinolone carboxylic acid (figure 1), against clinical isolates of $N$ gonorrhoeae, $G$ vaginalis, and laboratory and clinical strains of $C$ trachomatis.

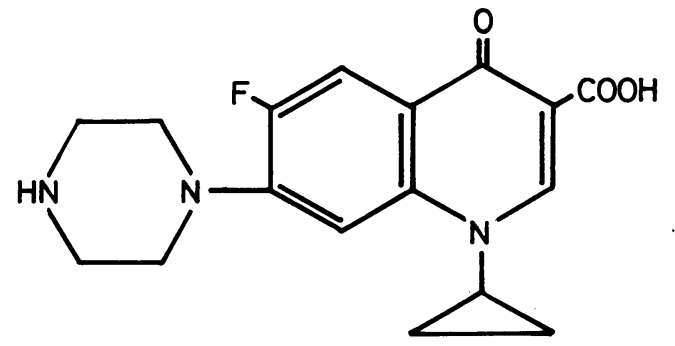

FIGURE The chemical structure of ciprofloxacin.

Address for reprints: Dr C A Hart, Department of Medical Microbiology, University of Liverpool, Duncan Building, Royal Liverpool Hospital, Prescot Street, Liverpool L7 8XW

Accepted for publication 23 January 1984

\section{Materials and methods}

The strains of $N$ gonorrhoeae and $G$ vaginalis were all clinical isolates and had been stored at $-70^{\circ} \mathrm{C}$ in glycerol broth until used. Seventeen of the gonococci were $\beta$-lactamase producers. The clinical isolates of $C$ trachomatis were four swab specimens of cervical secretions that had been stored at $-70^{\circ} \mathrm{C}$ in transport medium. The laboratory strains were BK (C trachomatis serotype $\mathrm{D} / \mathrm{E})$ and two strains of Lymphogranuloma venereum (MRC-4 and LGV-2), which had been obtained from Dr J Treharne (Institute of Ophthalmology, London WC1).

The antimicrobials were obtained as powders of stated potency from their manufacturers. The minimum inhibitory concentrations (MICs) of penicillin, ampicillin, tetracycline, rosoxacin, and ciprofloxacin for the bacteria were measured using an agar dilution method. Suspensions were prepared by scraping growth off plates of chocolatised blood agar and suspending the organisms in nutrient broth. Inocula containing about $10^{6}$ colony forming units (cfu) were applied using a multipoint inoculator. Suitable doubling dilutions of the antimicrobials were incorporated in DST (diagnostic sensitivity test) agar (Oxoid Ltd, Basingstoke, United Kingdom) containing $6 \%$ lysed horse blood. The plates were incubated at $37^{\circ} \mathrm{C}$ in a humidified atmosphere containing $10 \%$ carbon dioxide and examined after 24 hours and 48 hours. MICs of ciprofloxacin and rosoxacin for $C$ trachomatis grown in McCoy cell cultures treated with cyclohexamide were measured as described previously. ${ }^{4}$ After incubation for 72 hours at $35^{\circ} \mathrm{C}$, infected coverslips (two to four per dilution) were stained with Giemsa. Mature normal 
TABLE I Susceptibility of Gardnerella vaginalis and Neisseria gonorrhoeae to ciprofloxacin and other antimicrobials

\begin{tabular}{|c|c|c|c|c|c|c|c|c|c|}
\hline & \multicolumn{9}{|c|}{ No of isolates with MICs (mg/l) of: } \\
\hline & 0.01 & 0.05 & $0 \cdot 1$ & $0 \cdot 5$ & $1 \cdot 0$ & $2 \cdot 0$ & $4 \cdot 0$ & $8 \cdot 0$ & $>8 \cdot 0$ \\
\hline \multicolumn{10}{|c|}{$G$ vaginalis $(n=20)$} \\
\hline Ciprofloxacin & & & & 1 & 13 & 1 & 2 & 1 & 2 \\
\hline Rosoxacin & & & & & 1 & 10 & 4 & 3 & 2 \\
\hline Penicillin & 2 & 7 & 2 & 7 & 2 & & & & \\
\hline Ampicillin & 1 & 8 & 1 & 7 & 3 & & & & \\
\hline Tetracycline & & & i & & 11 & 7 & 1 & & \\
\hline \multicolumn{10}{|c|}{$N$ gonorrhoeae $(n=35)$} \\
\hline Ciprofloxacin & 35 & & & & & & & & \\
\hline Rosoxacin & & 30 & 4 & 1 & & & & & \\
\hline Penicillin & & 13 & 1 & 2 & 1 & 1 & & & 17 \\
\hline Ampicillin & & 4 & 4 & 8 & 1 & 1 & & & 17 \\
\hline Tetracycline & & & & 6 & 11 & 6 & 2 & 2 & 8 \\
\hline
\end{tabular}

inclusions were counted under dark ground microscopy ( $\times 400$ magnification), and abortive inclusions affected by antibiotic were counted by bright field oil immersion microscopy ( $\times 1000$ magnification).

\section{Results}

Table I shows that ciprofloxacin had a high intrinsic , activity against each strain of $N$ gonorrhoeae tested. All isolates were inhibited at a concentration of $0.01 \mathrm{mg} / 1$ irrespective of whether they were $\beta$-lactamase producers, relatively insusceptible to penicillin, or resistant to tetracycline. Ciprofloxacin was slightly more active than rosoxacin (mode MIC $0.05 \mathrm{mg} / \mathrm{l}$ ) against all the gonococci tested.

Ciprofloxacin was less active against $G$ vaginalis. Although $13(65 \%)$ of 20 isolates were inhibited at a concentration of $1 \mathrm{mg} / \mathrm{l}$, three isolates had MICs of $8 \mathrm{mg} / \mathrm{l}$ or more. Rosoxacin was again slightly less active (mode MIC $2 \mathrm{mg} / \mathrm{l}$ ), but all isolates were inhibited by penicillin or ampicillin at a concentration of $1 \mathrm{mg} / \mathrm{l}$.

Table II shows that all the chlamydiae tested, whether clinical or laboratory isolates, were inhibited by ciprofloxacin at a concentration of $2 \mathrm{mg} / \mathrm{l}$. This concentration is the chlamydial equivalent of the minimum bactericidal concentration, as no morpho-

TABLE II Activity of ciprofloxacin against Chlamydia trachomatis

\begin{tabular}{lll}
\hline & \multicolumn{2}{l}{ Concentrations $(\mathrm{mg} / \mathrm{ll})$ inhibiting: } \\
\cline { 2 - 3 } Chlamydial isolates & Normal inclusions & All inclusions \\
\hline Laboratory strains & & \\
BK & $0 \cdot 5$ & $2 \cdot 0$ \\
MRC-4 & $1 \cdot 0$ & $2 \cdot 0$ \\
LGV & $0 \cdot 5$ & $1 \cdot 0$ \\
Clinical isolates & & \\
15985 & $2 \cdot 0$ & $2 \cdot 0$ \\
16028 & $1 \cdot 0$ & $2 \cdot 0$ \\
16032 & $1 \cdot 0$ & $2 \cdot 0$ \\
16064 & $1 \cdot 0$ & $1 \cdot 0$ \\
\hline
\end{tabular}

logical evidence whatsoever of intracellular growth was detectable. At lower concentrations $(0.5 \mathrm{mg} / \mathrm{l}$ to $2 \mathrm{mg} / \mathrm{l}$ ) although the formation of normal mature inclusions was inhibited, some smaller abnormal inclusions were still visible. A similar gap between chlamydiastatic and chlamydicidal concentrations has been described for $\beta$-lactam antibiotics ${ }^{4}$ and for chloramphenicol. ${ }^{5}$ In contrast BK and LGV strains required concentrations of rosoxacin of $4 \mathrm{mg} / \mathrm{l}$ and $2 \mathrm{mg} / \mathrm{l}$ respectively to inhibit the formation of normal inclusions and $8 \mathrm{mg} / \mathrm{l}$ and $4 \mathrm{mg} / \mathrm{l}$ respectively to inhibit all inclusions.

It was necessary for ciprofloxacin to be present throughout the $\mathbf{7 2}$ hour incubation period to inhibit the laboratory strains (BK, MRC4, and LGV). If the medium that contained antibiotic was removed and the infected monolayers washed and fed again with medium free of antibiotic after either 24 or $\mathbf{4 8}$ hours and the monolayers incubated for a further $\mathbf{4 8}$ hours the formation of normal inclusions was not completely inhibited at a concentration of $4 \mathrm{mg} / \mathrm{l}$.

\section{Discussion}

Ciprofloxacin showed slightly better activity against gonococci than the related quinolone, rosoxacin. As has been shown for rosoxacin, ${ }^{6}$ ciprofloxacin was as active against $\beta$-lactamase producing and tetracycline resistant gonococci as against sensitive strains. In comparative clinical trials, rosoxacin in a single dose regimen was found to be as effective as either penicillin $^{7}$ or spectinomycin ${ }^{8}$ in treating uncomplicated gonorrhoea. In the former trial, ${ }^{7}$ however, $33 \%$ of men developed postgonococcal urethritis.

In Liverpool about half of the women with untreated gonococcal cervicitis are concurrently infected with $C$ trachomatis. ${ }^{9}$ A single antimicrobial agent active against both gonococci and $C$ trachomatis would greatly simplify the management of such infections. The replication of each of the strains of $C$ trachomatis tested was completely inhibited by cipro- 
floxacin at a concentration of $2 \mathrm{mg} / \mathrm{l}$. Serum concentrations of $3 \mathrm{mg} / \mathrm{l}$ can be achieved after a single oral dose $(500 \mathrm{mg}$ ) of ciprofloxacin (Bayer Ltd, United Kingdom, unpublished observation). If the serum concentration reflects the concentrations achievable at the sites of infection, our in vitro results would suggest that a clinical trial of ciprofloxacin in chlamydial or mixed chlamydial and gonococcal infections should be mounted. As prolonged (72 hour) in vitro exposure of chlamydia to ciprofloxacin would be required to inhibit growth, even under the artificial single cycle growth conditions of tissue culture in the case of BK strain (typical of most genital tract isolates), a single dose regimen would not be expected to be effective. Prolonged treatment for up to two weeks might be necessary.

\section{References}

1. Percival A, Corkhill JE, Arya OP, et al. Penicillinaseproducing gonococci in Liverpool. Lancet 1976; ii: 1379-82.
2. Taylor-Robinson D, Thomas BJ. The role of Chlamydia trachomatis in genital tract and associated diseases. $J$ Clin Pathol 1980; 33:205-33.

3. Stolz E, Nayyar KC. Corynebacterium vaginale infection. In Harris JRW, ed. Recent advances in sexually transmitted diseases-2. Edinburgh: Churchill Livingstone, 1981;229-37.

4. Hobson D, Lee $N$, Bushell AC, Withana $N$. The activity of $\beta$-lactam antibiotics against Chlamydia trachomatis in McCoy cell cultures. In: Mårdh P-A, Holmes KK, Oriel JD, et al, eds. Chlamydial infections. Amsterdam: Elsevier Biomedical Press, 1982;249-52.

5. Hobson D, Stefenidis D, Rees E, Tait I A. Effects of chloramphenicol on Chlamydia trachomatis infection in neonata conjunctivitis and in McCoy cell cultures. Journal of Hygiene (Cambridge) 1982;89:457-66.

6. Warren CJ, Shannon KP, Phillips I. In-vitro antigonococca activity of rosoxacin (WIN 35213). Br J Vener Dis 1981;57. 33-35.

7. Walsh RJ, Scott R, Bittiner JB, Shadihulla M, Slack RCB Acrosoxacin in the treatment of uncomplicated gonorrhoea. $\mathrm{Br}$ $J$ Vener Dis 1983;59:242-4.

8. Calubiran OV, Crinologo-Vizconde LB, Tupasi TE, Torre CA, Limson BM. Treatment of uncomplicated gonorrhoea in women: comparison of rosoxacin and spectinomycin. $\mathrm{Br} J$ Vener Dis 1982; 58:231-5.

9. Hobson D, Rees E. The role of Chlamydia trachomatis in female genital tract infections and in conjunctivitis of the newborn. In: Brumfitt $\mathrm{W}$, ed. New perspectives in clinica microbiology, London: Kluwer Medical Press, 1978; 109-23. 